\title{
Reflexiones sobre el ethos de la Grecia clásica desde la perspectiva de F.
}

\section{Nietzsche}

\author{
César Ignacio Gonzalo \\ UNNE - Facultad de Humanidades-
}

Resumen. Con motivo de lograr una interrogación de carácter crítico sobre el ethos de la Grecia Clásica, se procede a delimitarlo desde textos fuentes. Se pretende lograr con ello en primer lugar, el delineamiento de un campo fiable de conocimientos que den sustento a un segundo momento de interrogación, éste en carácter reflexivo, acerca de cómo se articula en su seno la emergencia de fenómeno filosófico. Ingresan aquí, conceptos básicos de la disciplina Ética en tanto y cuanto opera este doble movimiento de reflexión acerca de sus objetos perteneciendo ella misma, al objeto que interpreta. Será en este segundo momento donde operará una toma de posición crítica frente al objeto de estudio delimitado, ingresando con peso una serie de conceptos y perspectivas desde el pensador alemán Friedrich Nietzsche.

Palabras clave. Ethos, Grecia Clásica, Ética, Nietzsche, Filosofía

\section{Introducción}

Friedrich Wilhelm Nietzsche anuncia en Aurora (2000) que su trabajo es el de un subterráneo (p. 57). Nos encontramos con alguien que sospecha de todo lo que ha construido el hombre a partir del conocimiento; con alguien que deja de lado todo aquello que se ha dado por sentado en el humano por su mera estructura racional, y por cierto con alguien que duda sopesada y mortalmente sobre la moral. El Bien y el Mal nunca han sido puestos en duda, más bien se han erigido como las bases edilicias de toda la cultura occidental en cuanto formas que respaldan nuestro saber, tanto filosófico como científico y religioso. 
Se presenta como objetivo general de esta elaboración, una propuesta que refleje medianamente las inquietudes que se nos presentan ante el fenómeno del hombre en la época clásica con sus modos de conocer y relacionarse con el mundo. Por su parte, nos ha resultado ineludiblemente de una inquietud mayor tal fenómeno, a partir de selectivas lecturas realizadas sobre la obra de Friedrich Nietzsche referidas principalmente al fenómeno moral. Encarnando éste nuevas perspectivas relacionadas al origen y desarrollo mismo de la filosofía, y su posterior efecto en todo el saber del sujeto occidental. Nuestra hipótesis encuentra su enunciación en que toda construcción racional y/o espiritual elaborada por el ser humano desde sus inicios más remotos, responde a una construcción de función esencialmente moral.

Nuestro primer paso en esta elaboración académica, se precisa a partir de ciertas premisas abordadas respecto a los orígenes de los conceptos referidos a la moral; dicho de otra manera, una historia de los sentimientos morales. Esta mirada crítica que Nietzsche realiza sobre las bases teóricas de todo saber hasta él, intenta socavar las estructuras más firmes del conocimiento.

El marco sólido sobre el cual han de aplicarse reflexiones de contenido ético nos lo otorgará textos de la época, procedentes de sus representantes más significativos.

Realizadas las lecturas respectivas, se desarrollará lo que implica una fenomenología de la ética del conocimiento en la filosofía clásica, entendido esto como las implicancias que tiene toda forma de conocer en la conducta del ser humano hacia el mundo y sus caracteres principales en dicha circunstancia histórica. La potencialidad que esto acarrearía en su toma de conciencia nos parece de gran importancia en cuanto pone de manifiesto las capacidades reales del hombre frente a su entorno, y las consecuencias que ello ha acarreado en los modos de conocer del sujeto occidental.

Así, y en consecuencia a lo enunciado hasta aquí creemos que la problemática central del trabajo que nos ocupa será identificar y distinguir en calidad de objeto de estudio, el fenómeno del conocimiento filosófico en la época clásica a partir de los 
parámetros críticos ofrecidos por Friedrich Nietzsche, considerado aquel fenómeno como resultado y consecuencia de fenómenos morales.

El ethos en cuanto fenómeno, ha de ser considerado en el presente trabajo como aquello que responde a lo más propio de la especie humana. Su carácter, su conducta, sus modos de obrar y juzgar; toda una red que compone al hombre en su faceta tanto individual como social. De la toma de conciencia e identificación de tales aspectos en el ethos del hombre griego clásico dependerá el éxito de la investigación que nos ocupa. Para ello serán de suma utilidad los conceptos vertidos por Ricardo Maliandi (1991) en su trabajo Ética. Conceptos y problemas, ello con el fin de lograr definiciones precisas aplicadas a la Ética en cuanto disciplina.

La estructura del desarrollo investigativo dará sus primeros pasos con aclaraciones respecto al concepto de ethos; lo que se pretende con ello es dar el marco teórico correspondiente al específico objeto de estudio que se busca distinguir. Concepto de ethos, de reflexión ética, de las dicotomías morales por excelencia, etc. representan un momento fundamental en la consolidación del posterior tratamiento que haremos sobre el ethos de la Antigua Grecia.

A partir de aquel inicial paso, se procederá en un segundo momento a la elucidación de la posición ética representada por Friedrich Nietzsche. La lectura que dicho pensador hace de la historia, encarnada esta en los sentimientos morales y los orígenes mismos de valoraciones tan simples y fundamentales como Bueno y Malo, nos permitirá un abordaje de mayor precisión y profundidad respecto al ethos griego en su particular relación con el conocimiento. Es para ello, fundamental la posterior comparación y lectura que se haga de los textos fuentes sometidos a elección, lo cual derivará ya, en el meollo mismo de la hipótesis planteada.

Se encarará el presente trabajo desde una metodología que incorpore elementos hermenéuticos en cuanto la lectura de aquellos textos fuentes desde la perspectiva adoptada en la hipótesis. Una minuciosa y acabada tarea sobre aquellos textos dará el cuerpo teórico de mayor importancia a nuestra elaboración posterior. Por su parte, y como ya se ha enunciado, no se podrá dejar de lado el método genealógico adoptado por Friedrich Nietzsche en cuanto se quieran dilucidar 
conceptos de procedencia dudosa, cargados de valoraciones supersticiosas, hostiles al sentimiento vital. Por su parte, tomamos también aquella aguda observación psicológica que proclama el autor alemán por sobre muchos de los saberes consagrados como convenientes. Su ventaja se consagra en la vitalidad que confiere al hombre al despersonificarlo.

\section{2. Ética y ethos}

Resúltale imperativo al presente desarrollo teórico, aclarar algunos conceptos referentes a la ética en cuanto disciplina. Fundamentalmente aquellos que pongan en evidencia al objeto de estudio de la misma y los métodos que utiliza para abordarlos. Antes que nada, la disciplina Ética -como todo saber filosófico y científico- se manifiesta como un conjunto de conocimientos diferente de su objeto de estudio, y de tal modo nunca podría hablarse de Ética y ethos como si trabajáramos con acepciones semejantes.

La Ética es la tematización del ethos, según lo indica Maliandi (1991, p. 11). Es la conversión del ethos en tema, en el centro de atención de una disciplina. Por ello, cuando hablamos de Ética, será siempre en calidad de los aportes que pueda ofrecer desde su particular prisma respecto al ethos. Ahora, la cuestión inmediatamente siguiente concierne al modo en que tal disciplina aborda su objeto de estudio, al modo en que logra abstraer su tema para convertirlo en interés y fundamento de su búsqueda. Así entonces, la disciplina aborda al ethos desde una actitud reflexiva, entendida esta como una toma de distancia de aquel objeto para lograr de tal modo considerar sus aspectos esenciales. En dicha actitud, el sujeto se auto observa, mira hacia lo más concreto y próximo de sí: su conducta, sus modos de obrar, sus códigos de normas, etc., y con ello puede llegar a producirse una dificultad no menor: la confusión entre ambas esferas -la reflexión y lo reflexionado- Aquí resultará imprescindible la realización de una discriminación efectiva entre niveles de reflexión.

Hasta lo aquí mencionado, vale hacer alguna aclaración respecto a la aplicación que pueda hacerse de estos conceptos en relación al particular ethos que hemos 
optado por tematizar: el griego clásico, contexto socio-histórico que presenció el surgir del saber filosófico. Nos resulta pertinente en cuanto no será un abordaje "puro" el que se hará de dicho objeto de estudio; hablamos de pureza en el sentido de que no será un tratamiento original ni mucho menos uno privado de concepciones previas que en efecto, nos resultarán de base en tal elaboración. He aquí donde valen mencionar los aportes genealógicos que el trabajo de Friedrich Nietzsche nos ha brindado. Particularmente su lectura de la Historia (Nietzsche, 2006) nos ha resultado de vital importancia en la actitud que hemos tomado ante el ethos que nos ocupa. Lectura que vitaliza al lector y estudioso de un objeto que no es simplemente corpus de conocimiento. Aquí nuevamente retornamos a aquella dificultad de la ética en cuanto disciplina, -confusión de las esferas- en el sentido que debemos aclarar y aceptar que desde el prisma ético nietzscheano la actitud reflexiva -auto observación que implica una distancia de su objeto- necesariamente choca, se superpone y se le es superpuesto el objeto que le es de su interés. La observación psicológica como Nietzsche (1996) la denomina, es un mecanismo que no acaba en el hinchamiento de las arcas del saber humano, sino que necesariamente toma influencia en el ser humano interesado y lo capacita para la acción (2006, p. 10).

La discusión que se da en torno a la fallida toma de distancia que puede resultar de la reflexión ética respecto a su ethos es esencial; pues a condición de ello la disciplina Ética podrá ser categorizada como práctica o teórica. Se considera Ética práctica por ejemplo, a aquella que se encuentra en permanente simbiosis entre lo que observa en carácter reflexivo y las conclusiones que de ella deriva. No distingue mayormente entre lo que reflexiona y lo que predica. Veremos que esto en Friedrich Nietzsche cobrará enorme fuerza, pues nada resúltale de mayor improbidad que todo conocimiento que no se enlace directa y vitalmente a la constitución del individuo. Ante ello se dará la dificultad de distinguir aquellas esferas que se bifurcan pero que también encuentran necesaria relación.

Es de nuestra consideración que una reflexión de carácter ético necesariamente pone en jaque a su objeto de estudio, toma distancia de él pero no con fines de pura abstracción. Lo critica con la intención de no concederle valores absolutos, lo pone en 
observación y a partir de ello compara circunstancias que escapan al mero y simple hecho histórico. Se ponen en juego factores que influyen directamente en la vida del que toma seriamente tales reflexiones, en otras palabras puede decirse que se encuentra transformado por ellas. Entre estas circunstancias encontramos específicamente en Nietzsche las del origen de ciertas acepciones y conceptos, lo cual permite comprender específicamente algunos fenómenos que hasta entonces escapaban de la mano de los estudiosos de la historia del Hombre.

Vemos de este modo, una reflexión desde el plano ético que incorpora el contenido de aquella a su constitución vital. Una reflexión que se entremezcla con su ethos razonado, y que en consecuencia valora de un modo específico sus conclusiones. Es el caso de Nietzsche quien interpela fundamentalmente el fenómeno del ethos desde las oposiciones brindadas por la dicotomía axiológica (Maliandi, 1991, p. 31). Una polarización de carácter vertical al decir de Maliandi (1991, p. 31) que considera su objeto a partir de categorías que indican superioridad o inferioridad de carácter, o sea, aquello que nos es más propio. De esta prioridad axiológica que surge en Nietzsche para elaborar sus pensamientos, se deduce una inclinación hacia valores que exaltan o reducen lo vital en el ser humano; hacia conclusiones que lo llevan a considerar de un modo radical aquello que hasta él ni había sido puesto en duda.

Pero antes de seguir avanzando en lo que respecta al meollo mismo de la reflexión ética en Nietzsche; resulta de suma importancia realizar una aproximación conceptual al ethos, sin dudas protagonista en el desarrollo del presente trabajo. Su valor reside nada menos en que se presenta como el cuerpo sobre el que versará toda actitud reflexiva del que se dirige desde la mirada proporcionada por la disciplina Ética. "En el lenguaje filosófico general, se usa hoy "ethos" para aludir al conjunto de actitudes, convicciones, creencias morales y formas de conducta, ya sea de una persona individual o de un grupo social, o étnico, etc..." (Maliandi, 1991, p.14)De este modo, se presenta como algo real, pasible de ser considerado desde la perspectiva histórica y por ende con el posible valor de documento histórico. Dice al respecto Maliandi: "El ethos es un fenómeno cultural (el fenómeno de la moralidad), que suele presentarse con aspectos muy diversos pero que no puede estar ausente de ninguna 
cultura. Es (...) la facticidad normativa que acompaña ineludiblemente a la vida humana" (Maliandi, 1991, p.14) Vemos aquí que además de poseer una existencia real en el espacio-tiempo -por ello es Historia-, el ethos acompaña al hombre en su Naturaleza más íntima. Es aquello que lo determina en su devenir como ser racional y social.

Comprendido el ethos en sus aspectos más generales, cabe aun hacer algunas aclaraciones respecto a su estructura etimológica, cuestión no menor para el enfoque que se tratará de realizar posteriormente sobre ciertos fenómenos del ethos griego. Dos sentidos abarcan el origen de dicha acepción, tan antigua esta como la cultura griega misma: êthos por un lado, refiriéndose a lo revelador de lo más íntimo y personal de un hombre; y éthos que por el otro, indicaría hábito o costumbre. Estas dos maneras de comprender el término no se excluyen, más bien se complementan en una relación causal: el hábito forjando el carácter o viceversa, el carácter forjando al hábito. En el juego semántico que podemos realizar entre ambas acepciones se encuentra una clave para comprender la lectura nietzscheana realizada respecto al prisma ético que intentamos realizar sobre el ethos griego como fenómeno político, social y cultural. Nos topamos en tal punto, con una radical toma de posición por parte del mencionado pensador alemán donde el carácter del hombre, su modo de ser, es el que deberá tomar las riendas del hábito y no viceversa, como lo denunciará una y otra vez. Como veremos más detalladamente en el próximo capítulo, será en su famoso aforismo del "Concepto de la moral de las costumbres" (Nietzsche, 2000, p. 67), donde quedará muy clara su posición al respecto. El hábito ha tomado al hombre bajo su protección, dándole forma a su carácter e individualidad. Nada más reprochable de considerar desde aquella perspectiva que entiende el sentido del ethos en lo más íntimo de la naturaleza humana.

Se han aclarado algunos conceptos propios de la disciplina Ética y luego intentado correlacionarlos con algunos rasgos del pensamiento nietzscheano con el fin de ir acercándonos de forma gradual y progresiva a un método de investigación que nos permita dejar lo mayormente en claro la problemática del trabajo que nos ocupa. Pensamos que se erige como una dificultad de importante consideración la referida a 
la toma de distancia que debe tomar el pensador respecto a su objeto. Dicha tarea no es sencilla en cuanto se da con suma frecuencia que aquellos valores que han de ser estudiados ingresan en la actividad reflexiva misma con el estatus de criterios de evaluación; ocurre esto con el carácter pre-reflexivo del conocimiento ético. Tarea difícil además, por ser riesgoso caer en el exceso opuesto: esta es la actitud de la Meta ética en cuanto toma una distancia tan grande de su objeto que deja de ser reflexión (Maliandi, 1991, p. 39-40). En ambos casos ocurre que la nitidez del objeto por analizar e interpretar se pierde, ya sea por un acercamiento in extremis al mismo, como por un alejamiento igual de pronunciado. Por un lado, una solución posible puede ser la aplicación sistemática de las categorías éticas (dicotomías) al fenómeno puesto en la lupa, a fin de mantener la distancia pertinente que nos ofrece todo saber universal con su consiguiente formulación de leyes necesarias. Por otro lado, y a fin de no alejarnos excesivamente de nuestro objeto, aplicar aquella lectura histórica que Nietzsche inquiere para la revitalización del hombre en cuanto individuo, ajeno al hábito como pedagogo.

\section{3. a) La intentio obliqua como observación psicológica}

La observación psicológica sobre la cultura presenta en Nietzsche la posibilidad de reflejar cruda y concretamente lo Humano, demasiado humano. En el justo ejercicio de tal facultad, el hombre es un agudo observador de su conducta y la de ajenos; lo cual y en cuanto actitud procedimental- pone en evidencia las herramientas que el autor toma de la actitud científica en lo que a su carácter metodológico refiere. En el caso específico de Nietzsche se descubre esta actitud de observación como método, pero atravesada fuertemente por y hacia el concepto de lo moral. Es clara la alusión que al respecto se encuentra en el primer aforismo de su sección segunda: "Ventajas de la observación psicológica. (...) forma parte de los medios por los que se puede aliviar la carga de la vida" (Nietzsche, 1996, p. 64). Este proceder permite, desde un primer momento, poner a la conducta humana (ethos) en el plano de los objetos a pensar, estudiar y cuestionar. 
La observación psicológica por su parte, requiere de una actitud que no repare en las ventajas o dificultades que usualmente afectan al hombre ordinario; más bien se plasma en una actitud de sospecha necesaria ante todos estos sentimientos en cuanto construcciones históricas. Dice Nietzsche (1996) al respecto: “...se ha hecho necesario el despertar de la observación moral, y no puede ahorrársele a la humanidad el cruel espectáculo de la mesa de disección psicológica y de sus escalpelos y pinzas" (p. 66). Obsérvese en dicha cita la ya mencionada relación que el pensador alemán refiere a los métodos ofrecidos por las ciencias y su objeto de estudio.

El sentimiento moral como pasible de construcción durante su curso histórico es un punto central en el desarrollo de esta segunda sección, pues buscamos como objetivo una idea medianamente clara de la metodología utilizada por el autor, el objeto de dicho trabajo y sus características primordiales. En cuanto a la metodología, hemos ya referido someramente una clara utilización de herramientas procedentes de la tarea científica. Mientras que en lo que al objeto importa, es donde nos encontramos en el punto presente de discusión: el sentimiento moral como construcción histórica.

Volviendo de lleno al tema del objeto de esta aguda observación propuesta por Nietzsche, nos encontramos enfrentándonos al corpus de los sentimientos morales. En él, percibe el estadio en el que se manifiesta la condición humana en cuanto sujeta a la tradición de una autoridad incuestionable. Todo ello será pasible de observación en tanto ha sido declarado dicho corpus moral, como mera construcción histórica.

Desde el principio de su obra, Nietzsche aboga por un trabajo minucioso y cansino, da cuenta de ello en un sentimiento de nostalgia personal solo salvable por la tarea solidaria: colaboradores en la tarea reflexiva sobre lo humano, demasiado humano. Más ello es resultado de que se encuentra frente una sociedad compuesta por una serie de sentimientos que la vuelven decadente y obtusa en cuanto no reflexiona sobre los motivos de su accionar cotidiano.

La necesariedad en este arte de la sospecha, se fundamenta en la condición natural del hombre. El error que tantos dolores de cabeza le ha reportado tiene su base principal en la distinción que se ha hecho respecto a los demás seres bajo 
fundamentos metafísicos. Originalmente, en los caracteres que asignó a conductas determinadas su origen solo podía ser distinguido según el provecho que reportasen. Allí se encuentra la raíz moral criticada por Nietzsche, y es en tal situación donde operan los sentimientos morales desde su inicio para posteriormente dar cuenta de un olvido que deja de lado las meras consecuencias de aquellos actos: pasan a ser valiosos en sí mismos. Esto es resumido claramente en el importante aforismo número 39 cuando dice: "se transfiere el ser bueno o malo a los motivos y se consideran a los actos en sí como moralmente ambivalentes" (Nietzsche, 1996, p. 68). La predicación de bueno o malo de una determinada conducta pasa a abarcar la totalidad del hombre, y no ya a sus acciones particulares. Consecuencia de lo mencionado es que emerge el concepto de responsabilidad en el ser humano, pues cada una de sus conductas refiere a una totalidad de la que debe hacerse cargo. La conducta es valorada en sí misma, ya sin tener en cuenta sus consecuencias. Con ello "se hace así sucesivamente al hombre responsable de sus efectos, luego de sus actos, luego de sus motivos y, por último de su ser" (Nietzsche, 1996, p. 68)

Nos encontramos aquí ante uno de los puntos centrales en el pensamiento de Friedrich Nietzsche. Se trata de una teoría sobre la irresponsabilidad del ser humano en cuanto a todo lo que lo afecta: "Nadie es responsable de sus actos ni de su ser; juzgar es tanto como ser injusto" (1996, p. 68). No es menor la propuesta, pues en cuanto se siga tal hilo de inferencia nos enfrentamos a la supresión total del concepto de libertad, prevaleciendo la necesidad en cada una de las acciones humanas. Ocurriendo que en esa suposición que tiene el hombre de la afirmativa existencia de su libertad, se dan todos sus dilemas morales; los cuales lo autodividen: "En la moral el hombre no se trata como individuum, sino como dividuum" (Nietzsche, 1996, p. 76) Ahora, ¿qué se puede decir sobre estos sentimientos morales que dividen al hombre? Está claro en el autor que no se la puede suprimir de la historia del hombre; es más, en algún momento la considera necesaria en cuanto se observa la naturaleza salvaje y destructiva de éste: "La bestia en nosotros quiere que se le mienta; la moral es la mentira necesaria para que no nos destruya" (Nietzsche, 1996, p. 68). Si bien la hipótesis lo ha sumido en el error, también lo ha alejado del mundo de las bestias. En 
resumen, vemos que no se aborrecen del todo los sentimientos provocados por aquellas fuerzas morales. Hay un reconocimiento por parte de Nietzsche en cuanto son "el antecedente necesario, no lo contrario...". Lo contrario se aclara, refiere a la moral del porvenir; la postulada por nuestro autor.

Esta moral necesaria e histórica, ha devenido en una carga insoportable para el hombre. Ya no es posible sostenerla más. No se le debe negar el reconocimiento que merece, más ello debe realizarse en un acto desdeñoso a fin de ubicarla en su debido lugar: algo ridículo y pasado. En cuanto histórica, es de la intención de quién lleve adelante una tarea de observación psicológica sobre lo humano, poder vislumbrar la estructura sobre la cual descansan dichos sentimientos. Para ello es de suma importancia el rol de la cultura, depositaria por excelencia de las valoraciones morales activas. En cuanto se acaten o desobedezcan los cánones de dicha estructura ambivalente, se nominaliza la conducta humana en buena/mala y por ende moral/inmoral: "<Inmoral $>$ significa por tanto que uno no siente, o todavía no lo bastante intensamente, los motivos superiores, más sutiles, más espirituales que ha aportado la respectiva nueva cultura" (Nietzsche, 1996, p. 68). Vemos aquí entonces, un sistema moral acuñado históricamente y anclado en la cultura. Los hombres divididos por la responsabilidad, cargan sobre sus espaldas estas edificaciones de siglos de antigüedad.

\section{b) Nietzsche y el origen del conocimiento}

Si hay alguna cuestión sobre la cual Friedrich Nietzsche no dudará en desmitificar, será sobre el valor del conocimiento. Este, según su opinión, se originaría en cierta forma desde una metáfora, entendido esto como el traspaso de una esfera a otra, comprendiendo la primera un estímulo nervioso que se corresponderá en una imagen (primera metáfora), para luego definirse en la palabra (segunda metáfora). En Nietzsche (2012) queda claro que lenguaje y conocimiento no se corresponden pues el primero no puede describir la cosa. Será en Sobre Verdad y mentira donde más claramente quedará enunciado esto: “En un rincón apartado del universo, donde 
brillan innumerables sistemas solares, hubo una vez un astro en el cual unos animales inteligentes inventaron el conocimiento. Fue el minuto más soberbio y falaz de la "historia universal", pero sólo un minuto" ( $p$ 25). Así entonces, considerando que el conocimiento se manifiesta como una creación caprichosa del humano en cuanto especie, podremos preguntarnos en función de qué opera tal acto. Dirá al respecto el pensador alemán, que es el poder lo que mueve los hilos de la especie. Todo acto de conocimiento es un acto de interpretación, y todo acto de interpretación es la expresión de una voluntad de poder. De este modo podemos hablar de interpretación como un re-interpretar continuo, y en tal sentido nunca podría comprenderse al conocimiento como objetivo o con pretensiones de objetividad.

De acuerdo a lo dicho en el párrafo anterior cabe aclarar que no solo el conocimiento ha pasado por invento del hombre, sino también recurre Nietzsche en ello a la religión, a las instituciones y a la moral. Con esto se pone en el tapete la cuestión causal entre todos estos aspectos -propios- del hombre. Cuestión que puede sintetizarse en como cada uno de ellos se han relacionado y puesto en funcionamiento. Por ejemplo, la relación entre el fenómeno moral y el fenómeno de la religión presentan enormes y profusos tratamientos que no solo en Nietzsche se han desarrollado. Más de lo que se tratará aquí es específicamente como el fenómeno moral ha intercedido crucialmente en la gesta del saber filosófico dentro de lo que se considerará como el ethos griego.

Por su parte y en lo que implica ya una crítica directa a los filósofos griegos, Nietzsche considerará como inviable y decadente toda actitud metafísica. Su animosidad ante el platonismo principalmente, se manifiesta ante aquel "mundo verdadero" ideado por Platón; ante aquel mundo del ser que se opone abiertamente al mundo de los sentidos. En tal punto es necesario y sumamente importante considerar que en aquella crítica subyace una más, de carácter menos visible sí, pero no menos relevante. Se trata de la carencia de sentido histórico que poseen aquellos metafísicos, pues al devenir oponen la permanencia del ser. Recordemos en ello lo enunciado por Parménides (2007) en su poema: 
"Voy a decírtelo ahora, pero presta atención a mis palabras, / las únicas que se ofrecen al pensamiento de entre los caminos que reviste la búsqueda. / Aquella que afirma que el Ser es y el No-ser no es, / significa la vía de la persuasión -puesto que acompaña a la Verdad-/ y la que dice que el No-Ser existe y que su existencia es necesaria, / ésta, no tengo reparo en anunciártelo, resulta un camino totalmente negado para el conocimiento" (p. 11-12)

La crítica que sobre la actitud metafísica y su carencia de sentido histórico se realiza, se da además en el manifiesto desdén que los "primeros filósofos" ejercen hacia el mundo de las "apariencias", lo que según el pensador alemán devendrá en un estilo de vida decadente.

Vimos con Parménides, una de las fuentes principales de la metafísica en la Filosofía griega, y con ella el inicio de un largo camino que Nietzsche no dudará de poner entre sospechas. Nos manifestamos acordes a tal actitud en cuanto manifestaremos como previas, las condiciones que permitieron tal "descubrimiento", limitándonos eso sí, a tratar de poner en evidencia aquellos factores. Dichos enunciados, como ya se ha dicho, procederán de la interpretación -re-interpretaciónde textos contemporáneos y próximos en el espacio-tiempo del que como ejemplo, se expuso líneas atrás.

A partir de entender al acto de conocimiento como interpretación, Nietzsche rechaza toda posibilidad de intuición en cuanto especie de conocimiento entendida aquella como certeza inmediata de la conciencia. El mundo externo y el mundo interno comparten ambos, el carácter fenoménico de lo "aparente".

El modo en que opera aquella "metáfora" entendida como conocimiento, posteriormente se complejiza en la figura del concepto. Éste, presenta la particularidad de guiarse por prácticas que indagadas en sus raíces, contiene significaciones diferentes y a veces hasta opuestas a las que culminarán por otorgarle un valor sublime. La sublimidad se comprende justamente como aquello que se ha iniciado en intenciones con fines más bien prácticas y que posteriormente solo ha encontrado 
nuevas desviaciones. Es la tarea principal que Nietzsche aboga desde su labor genealógica: el esclarecimiento original de conductas que gradualmente encuentran asidero en nuevas interpretaciones justificadas en la voluntad de poder del o de los agentes. Sera en su aforismo de El concepto de la moralidad de las costumbres (Nietzsche, 2000, p.67) donde expondrá aquel pensamiento, estableciendo por su parte que toda moral es obediencia a las costumbres, las cuales a su vez expresan "la forma convencional de evaluar y actuar" (2000, p. 67). A su vez, anexa tradición con moralidad, siendo causalmente dependientes. De esta manera se da un primer sesgo de aquello que nos interesa en el específico desarrollo del presente trabajo académico: el valor de la tradición en la Grecia clásica. El espíritu libre, tan glorificado por Nietzsche encuentra su raigambre originaria en los primeros héroes griegos: crueles, conquistadores, arbitrarios, violentos, poderosos, impredecibles, etc.; todos valores que encuentran un fin práctico inmediato, siendo esta la expresión más cruda de poder además de la moralidad del momento. La dependencia que posteriormente comienza a operar respecto a la tradición resulta fundamental en lo que consideramos el nacimiento del saber filosófico. La tradición para Nietzsche (2000) resulta ser sumamente nociva en cuanto no da razones de lo que ordena, se manifiesta como "una autoridad superior, a la que se obedece, pero no porque nos ordene algo útil, sino porque simplemente lo ordena" (p. 68) El temor que funda su obediencia misma se encuentra sublimado en tanto presenta cualidades supersticiosas, no comprendidas por el conminado a obedecerlas.

Hacemos un alto aquí en tanto resulta imperativa alguna aclaración. Vimos hasta aquí nociones respecto al surgimiento de palabras, valoraciones y conceptos, pasando a considerar el modo en que consiguen anquilosamiento o en otras palabras, acatamiento. La cuestión no es menor, pues empieza a otorgarnos bases para posteriores interrogaciones e investigaciones, modos básicos en los que se manifiesta la reflexión ética (Maliandi, 1991, p. 19). En la lectura a realizar de los textos fuentes pertinentes, antepondremos entonces nociones como los de tradición, sublimidad, moralidad y costumbre desde la perspectiva ofrecida por Friedrich Nietzsche; a fin de 
que puedan aclararse aún más los objetivos perseguidos aquí y lograr con ello el enfoque correspondiente.

Concepto como el de tradición resultará fundamental en cuanto creemos que la filosofía como estilo de vida -esto se iniciaría con Sócrates- , impondrá a su manera nuevos valores, nuevas costumbres y modos de obrar; coincidiendo todo ello en la novedad de un específico ethos. Retomemos al pensador alemán para aclarar aún más dicho punto: “...esos moralistas que, como es el caso de aquellos sucesores que seguían las huellas socráticas, aconsejan al individuo la moral del dominio de sí y de la moderación como su ventaja más propia, así como la sobriedad como la clave de su dicha personal..." (Nietzsche, 2000, p. 68) El modo en que tales valores -moderación, templanza, dominio de sí- tornarán en costumbre en el ethos de la Grecia clásica, es un proceso por el cual transcurren infinitas circunstancias, sean políticas, económicas o militares. Más ello a nuestro criterio, donde mejor se verá reflejado será en la expresión considerada justamente más influyente de la época, circunscripta ella en la expresión literaria filosófica. Con esto queremos argüir que la filosofía griega toma su concepción de todo un contexto no pasible de ser encerrado en la genialidad de un puñado de hombres. Es el ethos griego el que ha posibilitado tal fenómeno y en cuanto ello, la disciplina Ética se torna indispensable para esclarecerlo.

Respecto a aquellos moralistas -discípulos socráticos- Nietzsche (2000) no pondrá en duda su originalidad, pues toda una tradición se les oponía: "Estos han de ser excluidos de la comunidad por ser inmorales y son, en el más profundo sentido del término, malvados [bôse]" (p. 69). Con esto, Nietzsche intenta demostrar en toda su dimensión la fuerza que posee la moralidad de la costumbre, siendo la comunidad misma la que la justifica y pone en acción; la cual por su parte excluye la posibilidad del individuo -el crimen del individuo es el crimen de la comunidad- .

\section{4. a) El ethos griego como condición de posibilidad}

Pocos son los que discuten el carácter seminal que la cultura griega ha representado sobre la civilización occidental. Sus influencias se extienden desde el 
ámbito del conocimiento -filosofía y ciencia- hasta la lengua, las artes y sus sistemas políticos. Los factores predominantes en la cultura del occidente actual, deben gran parte de su funcionamiento a aquella pequeña polis.

Más la cuestión que se suscitará en el presente capítulo será la referente al específico surgir de una de sus facetas; responsable ella de ser una de las expresiones más acabadas de la genialidad y progreso de la cultura griega clásica. Naturalmente nos referimos a la filosofía, como se viene sugiriendo a lo largo de todo el presente trabajo.

La reflexión crítica que se realice sobre esta expresión única en su tipo, si bien será puesta en práctica con especial hincapié en los cuerpos teóricos elaborados por algunos de sus principales representantes -Platón-, no acabará en ella, extendiéndose así a referentes de la poesía -Homero- y de la tragedia -Esquilo, Sófocles- . Todo ello con la específica intención de elucidar aquello que dichos autores trataban de poner en evidencia como necesario para la polis griega, entendida esta como totalidad de lo real.

Llega el momento en donde nuestro interrogante resulta definido. Preguntas enunciadas en el siguiente sentido; ¿Cuáles circunstancias son las que posibilitan el surgimiento del saber filosófico?, ¿cómo funciona este proceso y su posterior culminación?, ¿es el saber filosófico una viva muestra de la voluntad de poder de una nueva casta? ; representan el meollo mismo de nuestra investigación. La reflexión que desde el campo ético oficiamos, resulta una auto-observación que la filosofía hace a sus condiciones de posibilidad.

\section{a) La conformación de una polis}

Cuando hablamos de la Antigua Grecia, conviene hacer una serie de aclaraciones. La conformación política de la polis en tanto unidad total, resultó ser más un Ideal que una realidad efectiva. Su máxima expresión se manifestó en Atenas, una de tantas ciudades-estados; y consecuencia de ello indicamos que la reflexión interpretativa que respecto a nuestras fuentes podamos realizar, será desde una 
evidente toma de posición pro-ateniense. Esta procedencia de sus principales representantes; -Heródoto, Tucidides, Jenofonte, Platón, Aristóteles, etc.-, indica una primera condición de los valores puestos aquí en la lupa de la reflexión ética.

Son de suma importancia las condiciones históricas que posibilitaron la emergencia de tales ciudades-estados; siendo algunas entre ellas: migraciones, batallas de menor y mayor relevancia, el sistema económico dominante, etc. Más ello no será de nuestra mayor atención, pues hemos tomado el saber filosófico específicamente en cuanto objeto de estudio y sus expresiones más nítidas, lo cual culminaría por hacernos claro la preeminencia de una casta con su correspondiente uso de la voluntad de poder que podía permitirse.

Las primeras expresiones no son escritas. Largo trecho ha de transcurrir hasta que la práctica de la enunciación de opiniones, teorías y obras artísticas de todo tipo por vía de la escritura, se normalice. Los poemas homéricos en sus orígenes, eran presentados oralmente, y solamente durante un largo devenir -que seguramente a Homero nunca preocupó-, la tradición será transcripta al papel. Resulta esto de vital importancia para nuestra investigación, pues consideramos que esa misma voluntad que ha de expresarse en los filósofos como muestra de un novedoso mecanismo de poder, cuenta con la conditio sine qua non de ser puesta al servicio de la polis de un modo hasta el momento, inédito. La filosofía en el momento en el que se nos hace conocer -en manuscritos, referencias, etc- , ingresa en lo público. Con ello el filósofo, pero también el poeta, el compositor de tragedias, etc., ponen su actividad intelectual al servicio de algo que los excede y que los impele hacia la normalización de su ethos.

Los poemas homéricos son fiel representación de ese abrupto cambio que se da respecto a una posición, referida esta a pensamientos, prioridades, conductas, códigos de normas, morales -obediencia a las costumbres- en relación a la Atenas de Platón y Aristóteles.

El desparpajo con el que el héroe homérico enfrenta al prójimo (Homero, 2006, p. 1), a las autoridades y a la vida misma es resultado de un conjunto de normas, conductas, opiniones y creencias. Esto a simple vista es una obviedad, pero resultará 
de mayor relevancia cuando se comprenda el mismo proceso en la elaboración de los sistemas filosóficos posteriores a Sócrates.

Será consecuencia de aquella forma de entender las relaciones humanas en Homero lo que motivará a la filosofía platónica construir su firme crítica a los poemas del primero. Se motivaría ello por constituir una influencia sumamente negativa para las clases sociales de la polis (Platón, 2014, p. 256). El infantilismo de los dioses, sus rasgos antropomórficos, sus angustias y pasiones, ponen en guardia al fundador de la Academia. Horadan el sistema educativo que necesita la ciudad. El crimen deja de ser sopesado en función de sus motivos como ocurre con la famosa Orestiada de Esquilo e ingresa en el campo de lo prohibido. Como también todas aquellas acciones motivadas por la ambición, la conquista, la fuerza, etc. Nietzsche dará cuenta de esta transvaloración. Su teoría sobe el origen de lo <bueno $>$ da a entender que fue una consideración que los poderosos realizaban. Sus criterios y conductas eran lo que daba cuerpo al "buen hombre". Se lee lo siguiente en la Genealogía de la Moral: "...fueron los buenos mismos, es decir los nobles, los poderosos, los hombres de posición superior y elevados sentimientos quienes se sintieron y se valoraron a sí mismos y a su obrar como buenos (...), en contraposición a todo lo bajo, lo abyecto, vulgar y plebeyo" (Nietzsche, 2008, p. 37)

Una nueva moralidad lucha por asentarse, es la enunciada por el discurso filosófico. Ya no es el líder despótico el que representa el valor social positivo. Atenas, como ciudad-estado precisará de otros valores si querrá sobrevivir a las inminentes invasiones provenientes de Oriente. Los desperdigados territorios que representan a la Grecia Antigua, convergen en la pluralidad de mandos. Es famosa por la ejemplaridad del caso, el furioso desacato en el cae Teucro ante Agamenón, poniendo en evidencia la frágil autoridad que este representaba para los Aqueos (Sófocles, 2000, p. 79-82).

Como se observa, en ambos cuerpos teóricos se presenta un discurso ético muy pronunciado. Representantes y transmitentes de sus virtudes, vicios y necesidades, no pueden escapar del ethos que los conforma. Ethos que responde a lo más propio del hombre, a su morada como podría interpretarse de la famosa sentencia de Heráclito: ethos anthropoi daimon. La figura del filósofo es revolucionaria para la época en tanto 
es la necesidad de nuevas condiciones de sociedad la que lo motiva a ir afinando sus métodos y campos de estudio. Que representen valores inferiores o superiores es una específica acotación que responde más bien a la reflexión que no se distingue del todo con lo reflexionado. Es por ello que en Nietzsche toda mirada hacia esta nueva casta de filósofos -si bien no con el encolerizamiento que demuestra ante el cristianismo- es casi una negación. Decimos casi porque no faltan las excepciones en las cuales la redime en calidad de necesaria: "La bestia en nosotros quiere que se le mienta; la moral es la mentira necesaria para que no nos destruya" (Nietzsche, 1996, p. 69) Si bien la hipótesis moral lo ha sumido en el error, también lo ha alejado del mundo de las bestias. En resumen, vemos que no se aborrecen del todo los sentimientos provocados por aquellas fuerzas morales. Hay un reconocimiento por parte de Nietzsche en cuanto son "el antecedente necesario, no lo contrario...". Lo contrario se aclara, refiere a la moral del porvenir; la postulada por el autor mencionado.

Esta nueva moralidad que intenta imponerse no es espontánea ni consciente de su intención por supuesto. Como ya se mencionó, consideramos que es a partir de la transmisión del saber filosófico desde la escritura que se preocupa por manifestar abiertos imperativos de carácter ético. Anteriormente -Parménides, Heráclito, Tales, etc-, la preocupación todavía se encuentra lejos del deber político. Sus primeras reflexiones acerca del origen del hombre (principio primero) responden antes, a la conformación de la Unidad; el descubrimiento de la facultad racional utilizada metódicamente y referida a la totalidad. Dilthey (1953) en su definición esencial de la filosofía encontrará como inequívocos aquellos rasgos de actitud intelectual y búsqueda de la totalidad .

Más si bien el ethos griego ha de modificarse desde el surgimiento de los primero pensadores (presocráticos), hasta la conformación de Atenas como ciudadestado, los caracteres esenciales de ese proceder novedoso se mantendrán. El carácter intelectual del filósofo y su sentido hacia la totalidad deberán pasar ahora, por el filtro de la polis.

Justicia, Bien, Amistad, Ley, Belleza, entre otros, son figuras conceptuales que comienzan a tomar nuevos sesgos. Se erigen como valores supremos, merecedores de 
toda la atención del ateniense que busca lo mejor para su polis. Será Platón (2000) quién en su obra de referencia, La República, discurrirá elocuentemente sobre el valor de la Justicia. La pondrá por encima de cualquier hombre y ya no más al servicio de las pasiones; convertidas estas de allí en adelante en lo reprochable y vil. Es en ocasión de ello de suma correspondencia el diálogo que Sócrates mantiene con Calicles en el Gorgias (Platón, 2013). El hedonismo defendido por el segundo corresponde al carácter del tirano (2013, p. 148-160), figura sumamente perjudicial para el progreso de la polis griega. La complejidad en el plano político, social, económico que la ciudad ateniense demuestra ya en el s. V a. C. es notoria y conduce ello a nuevas interpretaciones y soluciones. No por nada la ya mencionada República de Platón (2000) ocupa muchas de sus líneas en la puntual organización de la ciudad dividiéndola en clases. Consecuencia de ello y fruto natural de este campo fértil que resulta el discurso filosófico -más allá de sus efectivas consecuencias- termina por caer de maduro la postulación según la cual la ciudad debe ser gobernada por la clase de los filósofos. Vemos aquí una prueba de la acertadísima reflexión que Nietzsche realiza respecto a los creadores de costumbres y nuevos valores. La filosofía platónica se yergue como creadora de valores, de orden, presta para sí el control de la realidad en tanto es sabedor privilegiado de lo Bueno y lo Malo. Voluntad de poder como saberpoder.

\section{Conclusiones}

Consideramos que el ethos de la Grecia clásica ha sido posibilitador del desarrollo de la filosofía, entendida esta en cuerpos sistemáticos. Solo desde Platón surgen estos pormenorizados desarrollos, consecuencia de lo que hemos postulado como aquel ethos de la polis griega. La imperiosa necesidad que urge a la nueva realidad política de una concordante lectura de sí, se plasma en nuevas formas y discursos. La casta de los filósofos se presentará como artífices de esta lectura y no dudarán en algún punto de la toma de conciencia de este poder, reclamar la dirección 
política de la ciudad. El valor político del filósofo torna crucial en cuanto entiende éste, que solo a su cargo la ciudad-estado ateniense encontrará rumbo cierto. Relacionado a esto encontraremos numerosos tratados dedicados al buen y mal comportamiento del hombre. Es el caso de la mencionada República de Platón, el Gorgias, que más allá de discurrir frente al discurso político como rival de turno, no deja de plasmar un firme recetario para la vida buena. Más adelante será Aristóteles quién con su Ética nicomaquea como punto de referencia, seguirá con dicha línea de pensamiento. Línea que toma no pocos recursos pedagógicos para dirigirse a sus conciudadanos.

La reflexión en carácter de auto-observación que hemos dirigido desde la filosofía clásica hacia sí misma, nos ha brindado las herramientas oportunas para desarrollar el presente trabajo. El carácter ético de dicha intentio obliqua nos ha permitido a su vez, considerar aspectos que exceden a la filosofía misma. Ya no partimos de inéditas circunstancias para valorar el surgimiento del saber filosófico, más bien lo ubicamos como resultado de una serie de factores de neto carácter social y político. $Y$ en ello radica toda la fuerza del trabajo que hemos de concluir: la vital importancia de un espacio socio-político y su carácter de campo fértil para la emergencia de saberes que hagan de la singularidad de aquel.

Para el objetivo propuesto nos ha resultado de imprescindible base la lectura genealógica que Friedrich Nietzsche realiza de los sentimientos morales. El sentido histórico que a la misma le presta, nos impele a un alejamiento de los criterios que nos guían en la cotidianeidad de nuestros juicios. Entendido esto como el grado de abstracción necesario para la imprescindible toma de distancia respecto a nuestro objeto de estudio.

Finalizamos dicha elaboración estableciendo la necesidad con la que se presenta una reflexión de este carácter. Toda elucidación que pueda hacerse sobre un determinado ethos, nos presenta la posibilidad de comprender sus condiciones de producción en todos los aspectos. Del ethos griego específicamente, afluyen un conjunto de factores que culminan en el surgimiento del saber filosófico como una de sus expresiones. Una práctica cada vez más radical de tal observación nos permitiría ir avanzando cada vez más sobre el contexto que nos conforma como sujetos. 